\title{
Retinoma - the first identified case in Jordan
}

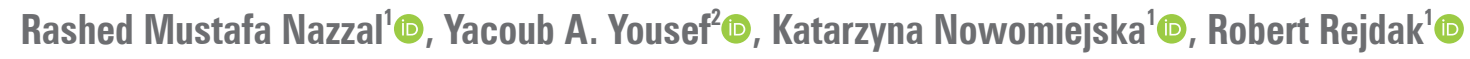 \\ 'Department of General Ophthalmology, Medical University of Lublin, Lublin, Poland \\ ${ }^{2}$ King Hussein Cancer Center, Amman, Jordan
}

\begin{abstract}
Retinoma (or retinocytoma) is a rare benign intraocular tumor with characteristic features and can be diagnosed clinically. In this article, we present a case report and a review of literature about retinoma. The case is about an incidentally diagnosed retinoma in an asymptomatic young female who presented for vision checkup and was found to have an intraocular translucent-grey, elevated mass extending into the vitreous cavity from the retina with the characteristic features of retinoma. The main differential diagnosis included retinoblastoma and astrocytic hamartoma. The mass showed no growth over a period of 6 months of follow up with colored fundus photography and ultrasound. This case is, to the best of our knowledge, the first case of retinoma diagnosed in Jordan.
\end{abstract}

KEY WORDS: retinoma; retinocytoma; retinoblastoma; Jordan

Ophthalmol J 2019; Vol. 4, 52-55

\section{INTRODUCTION}

Retinoma is a retinal tumor that is highly associated with retinoblastoma, but lacking malignant characteristics, that has been inaccurately initially considered as "spontaneous regression" of retinoblastoma [1]. However, clinical evidences do not support this hypothesis and suggest that retinoma rather represents a step towards retinoblastoma development [1-6]. Dimaras and colleagues demonstrated that retinomas display inactivation of both RB1 alleles, absence of proliferative markers, low level of genomic instability and high expression of the senescence-associated proteins; while retinoblastomas, on the other hand, show reduced expression of senescence-associated proteins and increased genomic changes, indicating progression from retinoma; which means that retinoma started from the beginning as retinoma, with the possibility to stay stable as retinoma, or rarely convert to retinoblastoma [7].

\section{CASE REPORT}

A 30-year-old female patient was referred to our center because of an intraocular retinal mass. The patient was asymptomatic and was incidentally found to have this lesion during a routine vision examination by another ophthalmologist. On examination, best corrected visual acuity was $6 / 6$ in both eyes, anterior segment examination was within normal limits and intraocular pressure was $14 \mathrm{~mm} \mathrm{Hg}$ in both eyes. Fundus examination of the left eye was normal while that of the right eye revealed an intraocular endophytic translucent retinal mass (Fig. 1) which was located in the superionasal quadrant protruding toward the vitreous cavity, surrounded by areas of chorioretinal atrophy and few spots of retinal pigment hyperplasia. The lesion has a cottage-cheese like appearance resembling post-radiation treated retinoblastoma. B-scan ultrasonography (Fig. 2) revealed hyperechoic lesion with high internal reflectivity and dense orbital shadowing consistent 


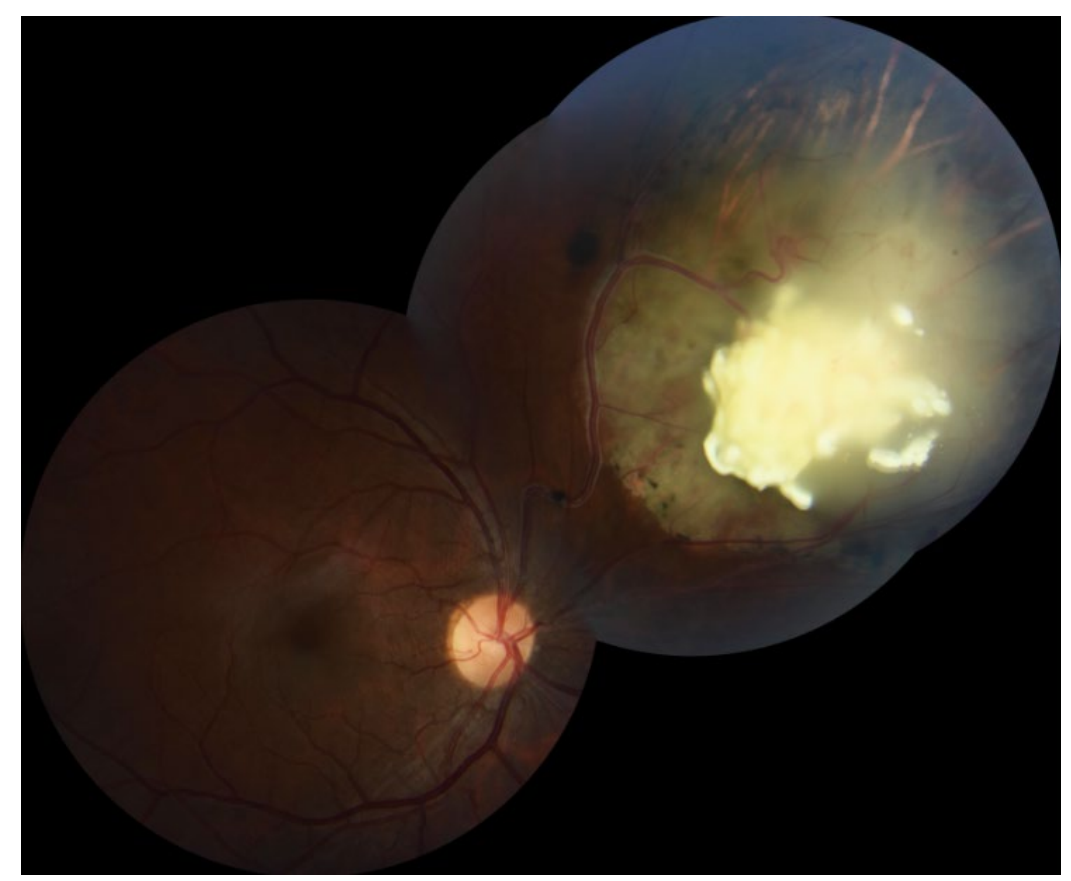

FIGURE 1. Color fundus photography of the right eye with retinoma

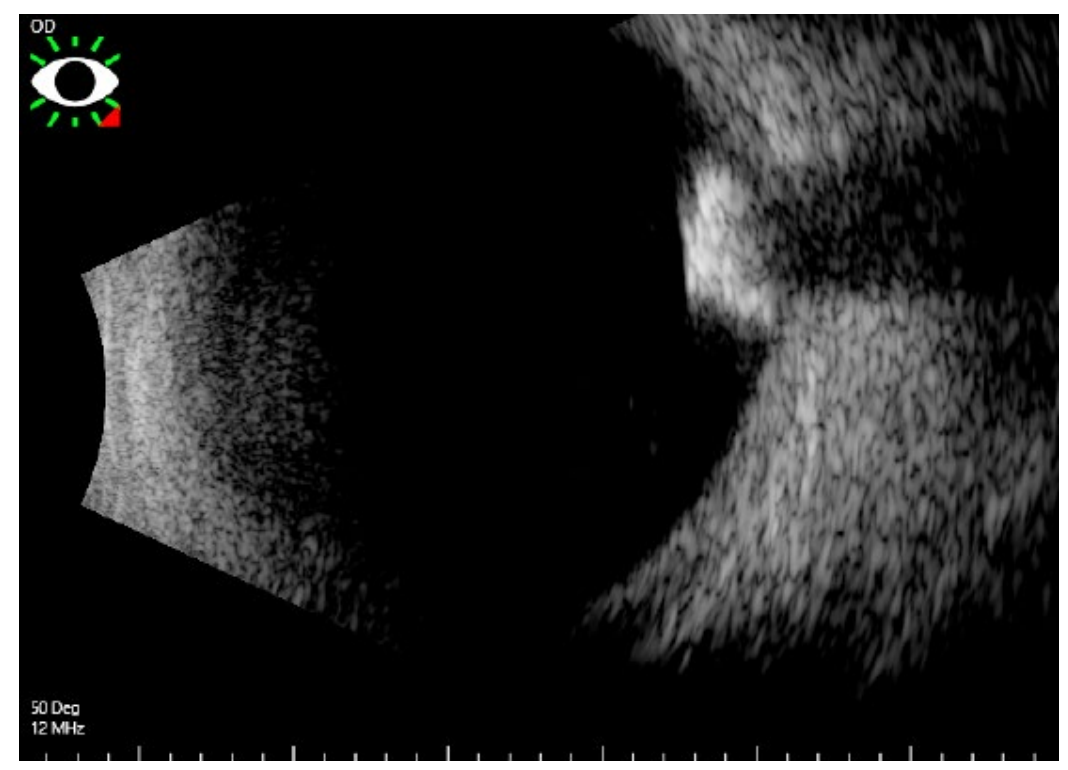

FIGURE 2. B-scan ultrasonography of the right eye with retinoma

with calcification inside the tumor. The patient was followed up over a period of 6 months by colored fundus photography and B-scan ultrasonography, which showed no growth and verified our diagnosis.

\section{DISCUSSION}

Retinoma is a rare benign tumor with incidence among retinoblastoma patients ranging between
$1.8 \%$ and $15.6 \%$ [5-7]. The disease is usually asymptomatic and may be diagnosed sporadically in a patient with retinoblastoma in the same eye, retinoblastoma in the other eye, or retinoblastoma in the family member $[5,6]$.

Margo et al. studied retinomas by light and electron microscopy and tested them with certain tissue markers and reported that these small placoid, noninvasive lesions were composed entirely of 
benign-appearing cells with numerous fleurettes and showed no necrosis or mitotic activity. Ultrastructurally, they were composed predominantly of neuronal cells exhibiting photoreceptor differentiation [4].

Ophthalmoscopically, these tumors are characterized by translucent mass, calcification, chorioretinal atrophy, and retinal pigment epithelium changes [1, $6,8]$. Calcified vitreous deposits is a recently described feature of retinoma in addition to the four classical features [9]. It was noted that up to $4 \%$ of retinomas may undergo benign cystic enlargement, which might be associated with an aggressive tumor potential [10].

Despite the characteristic ophthalmoscopic features mentioned above, certain entities, such as retinoblastoma and astrocytic hamartoma, can closely resemble retinoma. Retinoblastoma is usually diagnosed before the age of 5 and retinoma is usually diagnosed in adults. Although calcification is seen in both tumors, areas of chorioretinal atrophy and associated retinal pigment epithelial changes are uncommon in untreated retinoblastoma. In addition, dilated, tortuous retinal feeder vessels are a feature of retinoblastoma rather than retinoma. Characteristically, retinoblastoma will show growth within 4-6 weeks, whereas retinoma will appear unchanged. Astrocytic hamartoma is a benign retinal tumor and can also closely resemble retinoma because both lesions may be calcified. Calcification, when present, can demonstrate subtle differences, as it tends to be dull and chalky white in retinoma, whereas in astrocytoma it is more glistening yellow, resembling fish eggs. Surrounding retinal pigment epithelium alterations, a common finding in retinoma, is typically absent in astrocytic hamartoma as they are situated superficially in the retina [11].

Malignant transformation into retinoblastoma is rare $[3,5]$, although a new study reported higher transformation rate that might reach up to $12 \%$ [10]. In the unfortunate event that malignant transformation occurs, systemic chemotherapy combined with consolidation focal therapy has become the standard treatment for retinoblastoma [12], with external beam radiation as a less favored treatment option [13]. The incidence of second malignant neoplasms in RB1 gene mutation carriers with retinocytoma is unknown, but well documented [10].

Retinoma is considered a rare phenotype of RB1 gene mutation and carries the same genetic implication as retinoblastoma [14]. The exact reason of why some patients develop retinoma rather than retinoblastoma is not yet known, but hypothetically it may arise if the second hit occurred in a later stage of cell maturation when the precursor cell has a limited mitotic capability and is unable to accumulate further mutations [15].

Studies aimed at clarifying retinoma/retinoblastoma relationship at molecular level are rarely performed. This is principally due to the fact that retinoma tissue is very difficult to obtain since patients are not treated and retinoma/retinoblastoma mixed tissues are rarely reported in enucleated eyes [2]. However, from the few reported cases, which have been dissected and analyzed, it turned out that from genetic point of view, retinoma should be considered as retinoblastoma with autosomal dominant inheritance pattern involving a mutation in the RB1 gene locus on chromosome 13q14 [1, 2]. The diagnosis of retinoma strongly suggests the presence of the retinoblastoma gene, necessitating genetic counseling and frequent observation of the retinas in the individual and his offspring $[1,2]$. We suggest that the same mutations can cause either retinoma or retinoblastoma: benign hyperplastic nodules or retinoma when the mutations occur in relatively mature retinoblasts; and malignant retinoblastoma when the same mutations arise in immature retinoblasts [1].

Although retinoblastoma is a well-known tumor in Jordan and the reported epidemiological data indicates that the incidence of retinoblastoma in Jordan is similar to that reported in various countries of the world [16], this is the first case of retinoma diagnosed in Jordan.

\section{CONCLUSIONS}

It is of paramount importance to diagnose retinoma and differentiate it from retinoblastoma because the management plan for both is completely different; retinoblastoma necessitates urgent treatment while retinoma needs only observation. Nevertheless, these patients should be monitored for life because of the small risk of malignant transformation or associated second malignant neoplasms

\section{ACKNOWLEDGEMENTS}

None.

\section{CONFLICT OF INTERESTS}

None.

\section{REFERENCES}

1. Gallie BL, Ellsworth RM, Abramson DH, et al. Retinoma: spontaneous regression of retinoblastoma or benign manifestation of the mutation? Br J Cancer. 1982; 45(4): 513-521, doi: 10.1038/bjc.1982.87, indexed in Pubmed: 7073943. 
2. Sampieri K, Mencarelli MA, Epistolato MC, et al. Genomic differences between retinoma and retinoblastoma. Acta Oncol. 2008; 47(8): 1483-1492, doi: 10.1080/02841860802342382, indexed in Pubmed: 18785023

3. Eagle RC, Shields JA, Donoso L, et al. Malignant transformation of spontaneously regressed retinoblastoma, retinoma/retinocytoma variant. Ophthalmology. 1989; 96(9): 1389-1395, indexed in Pubmed: 2780006.

4. Margo C, Hidayat A, Kopelman J, et al. Retinocytoma. A benign variant of retinoblastoma. Arch Ophthalmol. 1983; 101(10): 15191531, doi: 10.1001/archopht.1983.01040020521003, indexed in Pubmed: 6626001.

5. Balmer A, Munier F, Gailloud C. Retinoma. Case studies. Ophthalmic Paediatr Genet. 1991; 12(3): 131-137, indexed in Pubmed: 1754160.

6. Singh AD, Santos CM, Shields CL, et al. Observations on 17 patients with retinocytoma. Arch Ophthalmol. 2000; 118(2): 199-205, doi: 10.1001/archopht.118.2.199, indexed in Pubmed: 10676785.

7. Dimaras H, Khetan V, Halliday W, et al. Loss of RB1 induces non-proliferative retinoma: increasing genomic instability correlates with progression to retinoblastoma. Hum Mol Genet. 2008; 17(10): 1363-1372, doi: 10.1093/hmg/ddn024, indexed in Pubmed: 18211953.

8. Lommatzsch PK, Zimmermann W, Lommatzsch R. [Spontaneous growth inhibition in retinoblastoma]. Klin Monbl Augenheilkd. 1993; 202(3): 218-223, doi: 10.1055/s-2008-1045586, indexed in Pubmed: 8510416.
9. Hadjistilianou T, De Francesco S, Martone G, et al. Retinocytoma associated with calcified vitreous deposits. Eur J Ophthalmol. 2006; 16(2): 349-351, indexed in Pubmed: 16703560.

10. Abouzeid $\mathrm{H}$, Balmer A, Moulin AP, et al. Phenotypic variability of retinocytomas: preregression and postregression growth patterns. Br J Ophthalmol. 2012; 96(6): 884-889, doi: 10.1136/bjophthalmol-2011-300896, indexed in Pubmed: 22328814.

11. Shah PK, Narendran V, Manayath GJ, et al. Atypical retinocytoma with diffuse vitreous seeds: An insight. Oman J Ophthalmol. 2011; 4(2): 8183, doi: 10.4103/0974-620X.83659, indexed in Pubmed: 21897624.

12. Yousef $Y A$, Nazzal RM, Khalil MB, et al. Management outcome(s) in eyes with retinoblastoma previously inadequately treated with systemic chemotherapy alone without focal therapy. Oman J Ophthalmol. 2017; 10(2): 70-75, doi: 10.4103/0jo.0JO 225 2015, indexed in Pubmed: 28757689.

13. Yousef $Y$, Mahameed I. External Beam Radiation Therapy for Retinoblastoma Resistant to Chemotherapy and Focal Treatment: Outcome and Predictive Factors. J Clin Exp Oncol. 2015; 04(02): 2-6, doi: 10.4172/2324-9110.1000140.

14. Abramson DH. Retinoma, retinocytoma, and the retinoblastoma gene. Arch Ophthalmol. 1983; 101(10): 1517-1518, doi: 10.1001/ archopht.1983.01040020519002, indexed in Pubmed: 6626000.

15. Gallie BL, Dunn JM, Chan HS, et al. The genetics of retinoblastoma. Relevance to the patient. Pediatr Clin North Am. 1991; 38(2): 299-315, indexed in Pubmed: 2006079.

16. Jaradat I, Yousef YA, Mehyar M, et al. Retinoblastoma in Jordan: an epidemiological study (2006-2010). Hematol Oncol Stem Cell Ther. 2011; 4(3): 126-131, indexed in Pubmed: 21982886. 